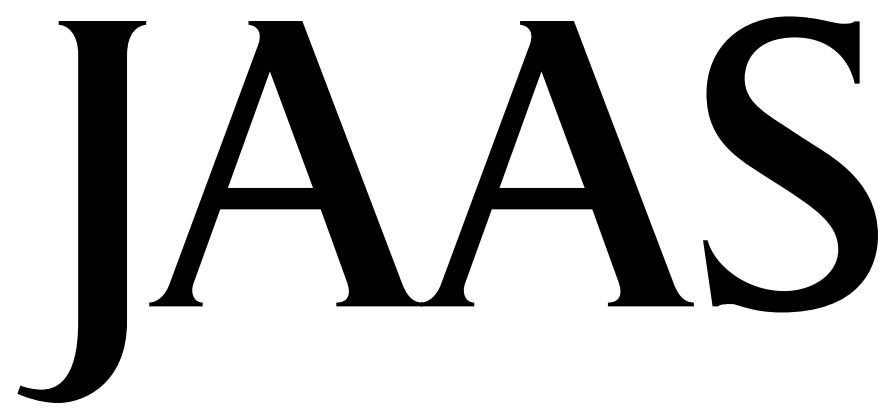

Journal of Analytical Atomic Spectrometry

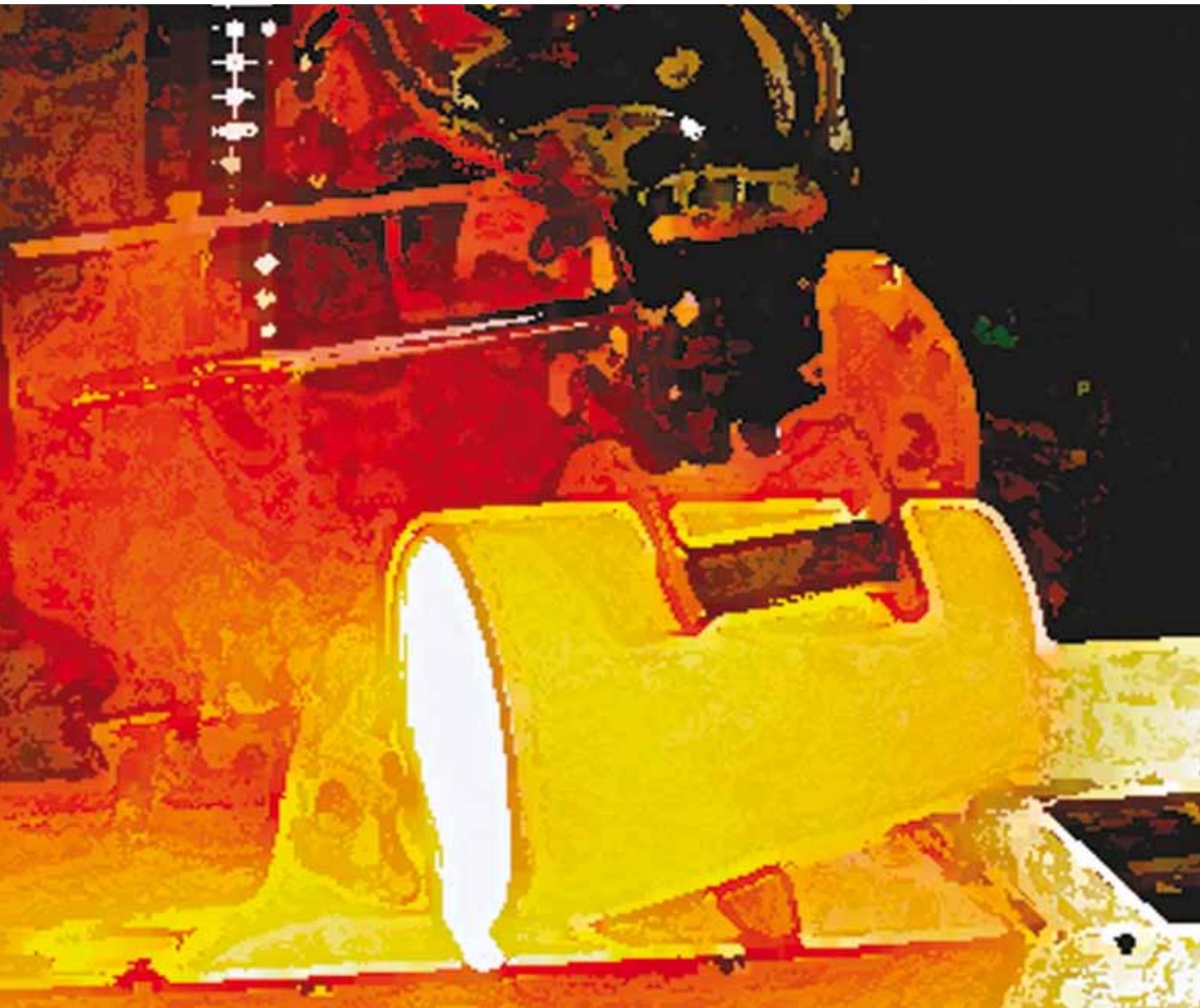

Themed Issue 2010 Winter Conference on Plasma Spectrochemistry

\section{PAPER}

Vanhaecke et al.

Femtosecond LA-ICP-MS analysis of a heavy metallic matrix: Determination of Pt group metals and $\mathrm{Au}$ inPb fire-assay buttons as a case study

\section{EDITORIAL}

Barnes

2010 Winter Conference on Plasma Spectrochemistry Fort Myers, Florida,

January 4-9, 2010

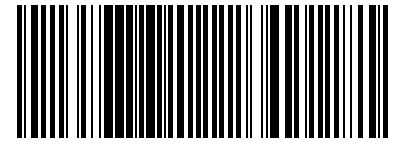

0267-9477(2010)25:8;1-A 


\title{
Femtosecond laser ablation-ICP-mass spectrometry analysis of a heavy metallic matrix: Determination of platinum group metals and gold in lead fire-assay buttons as a case study
}

\author{
Frank Vanhaecke, ${ }^{a}$ Martín Resano, ${ }^{b}$ Joachim Koch, ${ }^{c}$ Keith McIntosh ${ }^{d}$ and Detlef Günther ${ }^{c}$ \\ Received 9th February 2010, Accepted 26th April 2010 \\ DOI: 10.1039/c002746d
}

Owing to the shorter time interval during which energy is delivered to the sample material, femtosecond (fs) laser ablation is preferable over nanosecond laser ablation for metallic samples. In this project, the influence of various laser parameters - beam diameter, repetition rate and laser fluence - on the ablation of $\mathrm{Pb}$ as a heavy metallic matrix using an infrared $(\lambda=795 \mathrm{~nm})$ fs-LA system (150 fs pulse duration) was studied. The merits of $\mathrm{Ar}$ and $\mathrm{He}$ as carrier gases were compared and as $\mathrm{He}$ did not provide a substantial improvement in the limits of detection, while deposition of sample material on the window of the ablation chamber was more pronounced, Ar was selected for all further measurements. The effect on the ICP caused by the introduction of various amounts of sample aerosol was studied by monitoring the signal intensity for ${ }^{38} \mathrm{Ar}^{+}$. It was shown that maximizing the amount of sample ablated and thus, the amount of sample aerosol introduced into the ICP, did not result in maximum sensitivity, which was rather obtained under 'compromise' conditions. Subsequently, femtosecond LA-

quadrupole-based ICP-mass spectrometry (ICP-MS) was used for the determination of traces of the platinum group metals (PGMs) $\mathrm{Rh}, \mathrm{Pd}, \mathrm{Ru}$, Ir and $\mathrm{Pt}$ and of $\mathrm{Au}$ in $\mathrm{Pb}$ buttons obtained by fire assay of platiniferous ore reference materials. The signal of ${ }^{204} \mathrm{~Pb}^{+}$was used as an internal reference, correcting for variations in the laser ablation and transport efficiencies and in the instrument's sensitivity. The spectral interferences established for some of the target nuclides due to the occurrence of $\mathrm{Pb}^{2+}$ ions were successfully overcome by pressurizing the reaction cell with $\mathrm{NH}_{3}$. Quantification versus a calibration curve constructed on the basis of the results obtained for matrix-matched standards $(>99 \% \mathrm{~Pb})$ provided excellent accuracy, superior to those obtained using nanosecond LA-ICP-MS. Also the limits of detection were improved by a factor ranging between 3 and 10 and are $<0.010 \mu \mathrm{g} \mathrm{g}^{-1}$ for the most important PGMs (Rh, Pd, Pt) and Au. Several measures, such as the use of a large ablation cell and housing up to $10 \mathrm{~Pb}$ buttons, were taken to increase the sample throughput. In the same context, day-to-day reproducibility of the calibration curve was also examined. When recording a 'fresh' calibration curve every day, the average bias between the experimental results and the corresponding reference values was established to be $<2.5 \%$ for every target element. When using one calibration curve during three consecutive days, the bias still remains $<10 \%$, while the sample throughput is increased and analysis of several tens of buttons per day is feasible (10-15 min total analysis time per sample).

\section{Introduction}

The platinum group metals (PGMs) are used for a variety of purposes. ${ }^{1}$ Nowadays, large quantities are used for the manufacturing of car exhaust ${ }^{2}$ and industrial catalysts. In the catalyst that petrol-driven cars are equipped with, Pt and Pd catalyze the oxidation of incompletely burnt hydrocarbons and $\mathrm{CO}$, while $\mathrm{Rh}$ catalyzes the reduction of $\mathrm{NO}_{x}$ into less noxious gases $\left(\mathrm{H}_{2} \mathrm{O}, \mathrm{CO}_{2}\right.$ and $\left.\mathrm{N}_{2}\right)$. Diesel cars on the other hand, are equipped with a catalyst containing Pt only. PGM catalysts are

${ }^{a}$ Ghent University, Department of Analytical Chemistry, Krijgslaan 281-S12, 9000 Ghent, Belgium

${ }^{b}$ University of Zaragoza, Department of Analytical Chemistry, Pedro Cerbuna 12, 50009 Zaragoza, Spain

${ }^{c}$ ETH-Zurich, Department of Chemistry and Applied Biosciences, Laboratory of Inorganic Chemistry, Wolfgang-Pauli-Strasse 10, 8093 Zürich, Switzerland

${ }^{d}$ Anglo Research, PO Box 6540, Homestead, 1412, South Africa also used in, among others, the petrochemical industry and the production of nitric acid. Other industrial uses of the PGMs include their use as "containers" withstanding high temperatures (Pt and Ir crucibles, Pt equipment in the glass industry), in chemotherapeutic drugs and dental fillings and as vital components in high-end products, such as computer hard disks $(\mathrm{Pt})$, electronic components $(\mathrm{Pd})$ and sensors. Finally, a very substantial fraction of the $\mathrm{Pt}$ produced is used for the manufacturing of jewellery and watches and as a means of investment (bars and coins). As a result of the diverse and intense use of most of the PGMs, the global demand is high and could even further increase upon, e.g., the more widespread use of fuel cells, which are often announced as the energy source of the future, in which $\mathrm{Pt}$ is used as a catalyst. ${ }^{3}$ The main producer of $\mathrm{Pt}$ is South Africa, where platiniferous ores are obtained from the Merensky, UG2 and Platreef within the so-called Bushveld Igneous Complex. ${ }^{4}$ Other PGM mining is located in Russia, the US, Canada and Zimbabwe. Unfortunately, the content of the 
PGMs in the corresponding ores is never very high (for South African ores $<10 \mathrm{~g} \mathrm{ton}^{-1}$ ) and a series of physical and chemical treatments (flotation, smelting, wet chemical refining) are required to obtain the pure metals from the ores. The combination of all of these factors serves as an explanation for the high PGM prices, ranging currently (in times of an economical crisis) from $\sim 2800$ US $\$$ per oz (28.3495 g) for $\mathrm{Rh}, \sim 1700$ for $\mathrm{Pt}, \sim 500$ for $\mathrm{Ir}, \sim 500$ for $\mathrm{Pd}$ to $\sim 200$ for $\mathrm{Ru} .^{5}$ As a result, there is also interest in the recycling of these metals from, among others, used car exhaust catalysts and electronic scrap. ${ }^{6}$

As a result, the accurate and precise determination of the PGM concentrations in the ores and throughout the enrichment and purification or recycling processes is of crucial importance. For several reasons, however, the analysis of the ores in particular presents a considerable challenge, due to the relatively low concentrations of the target elements, their heterogeneous distribution within the matrix and the chemical properties of these elements, complicating dissolution. Fireassay procedures allow these drawbacks to be circumvented, as they permit the use of a substantial amount of ore (tackling the problem of heterogeneity) and involve extraction of the target elements into a molten collector (most often $\mathrm{Pb}, \mathrm{NiS}$ or $\mathrm{Cu})^{7^{7-9}}$ In the case of $\mathrm{Pb}$ fire assay, the $\mathrm{Pb}$ matrix can be subsequently removed by oxidative fusion, whereby $\mathrm{Pb}$ is converted into $\mathrm{PbO}$, which is absorbed by the porous $\mathrm{MgO}$ cupel material (preconcentration) and the prill obtained can be further analyzed in various ways (gravimetrically or after dissolution). The development of methods for direct analysis of the solid collectors is an appealing alternative, enabling sensitivity, sample throughput and problems related to incomplete recovery of some analytes upon digestion to be avoided. ${ }^{10}$ In earlier papers, we have presented an evaluation of the capabilities of laser ablation ICP-mass spectrometry (LA-ICP-MS) and other solidsampling techniques for the direct analysis of the $\mathrm{Pb}$ fire assay buttons obtained. ${ }^{11,12}$ In this work, the merits of a femtosecond LA-system for analyzing these materials were evaluated and compared to those characteristic for the nanosecond LA-system used in previous work.

Femtosecond lasers transfer the energy to the sample material in a considerably shorter time interval (for the LA-unit deployed in this work $\sim 150 \mathrm{fs})$ than solid-state $(\sim 3 \mathrm{~ns})$ or gas $(\sim 20 \mathrm{~ns})$ nanosecond lasers. ${ }^{13-17}$ As a result of this much faster transfer of energy, heating of the sample material is avoided and the material is ablated in a more controlled way (via an explosion-like ablation process ${ }^{18-20}$ ). As a result, the aerosol formed upon laser impact consists of finer particles and loosely bound agglomerates that are better 'digested' in the ICP, leading to a higher signal intensity and improved stability. ${ }^{21-24}$ Also elemental and isotopic fractionation effects are significantly reduced, ${ }^{20,24-26}$ leading to less stringent demands in terms of matrix-matching of external standards, ${ }^{27,28}$ while absence of isotopic fractionation provides ideal conditions for highly precise and accurate isotopic analysis via the combination of fs-LA and multi-collector ICP-MS. ${ }^{29}$ Finally, because of the absence of heating, the crater is better defined, making femtosecond lasers preferable over nanosecond lasers for micro-machining and spatially resolved analysis, ${ }^{17,18}$ especially for metallic samples. For all these reasons, analysis of the latter sample type should be largely improved when using a femtosecond LA device. ${ }^{21,23,28,30}$
In this paper, we report on the exploration of the analysis of an extremely heavy metallic matrix, practically pure $(>99 \%) \mathrm{Pb}$. In a first part of the paper, the influence of various LA parameters on the results obtained-beam diameter, repetition rate, laser fluence, type of carrier gas-were studied, as well as the effect changing these parameters has on the plasma conditions. The latter was accomplished via the simultaneous monitoring of a number of "indicator" signals, such as ${ }^{38} \mathrm{Ar}^{+},{ }^{40} \mathrm{Ar}_{2}{ }^{+}$or ${ }^{16} \mathrm{O}_{2}{ }^{+} \cdot{ }^{31,32}$

After optimization of the instrument settings, the method was characterized by documenting, among other, crater shape, penetration depth per laser firing, limits of detection and reproducibility. Finally, also the accuracy attainable was evaluated via analysis of $\mathrm{Pb}$ buttons prepared via fire assay analysis of platiniferous ore reference materials.

\section{Experimental}

\section{Samples and standards}

The production of the samples and standards was carried out at Anglo Research and is described in detail in reference. ${ }^{\mathbf{1 2}}$

Firstly, for the standards, a "mother button" bulk standard was prepared starting from assay grade (PGM-free) $\mathrm{Pb}$ foil and PGM sponges. Accurately weighed amounts of the PGM sponges were placed in folded $\mathrm{Pb}$ foil ('boat' shape) that was subsequently heated in a graphite crucible within a kettle furnace under $\mathrm{N}_{2}$ atmosphere at $1100{ }^{\circ} \mathrm{C}$ for $60 \mathrm{~min}$. The molten alloy thus obtained was cast into a water-cooled $\left(3{ }^{\circ} \mathrm{C}\right) \mathrm{Cu}$ mold. The ingot thus obtained was subsequently flattened to a $1 \mathrm{~mm}$ thick strip. Subsequently, each of the $\mathrm{Pb}$ buttons serving as external standards for calibration curve construction, was produced by adding a carefully weighed section of this strip to a known mass of $\mathrm{Pb}$ to produce the final ingot with similar heating (for $40 \mathrm{~min}$ ) and casting into its final form.

Four reference materials, all commercially available from Mintek (South Africa), from which $\mathrm{Pb}$ buttons were produced, were selected as samples: SARM 7B, SARM 64, SARM 65 and SARM 66. SARM 7B and SARM 65 are platiniferous ores from the Merensky reef and the UG2 reef, respectively. SARM 64 is a tailings sample from the flotation process - the first step in the beneficiation process, separating the PGMs from the ore matrix, and is thus lower in grade than the previously mentioned SARMs. It is derived from UG2 reef ore. SARM 66, on the other hand, is a flotation concentrate also from UG2 reef ore, thus showing higher PGM content and, probably, a higher degree of homogeneity.

Adequate amounts of these SARMs - typically around $50 \mathrm{~g}$, except for SARM 66, for which, based on its higher PGM concentrations, masses of approximately $7 \mathrm{~g}$ were used-were mixed with a flux, containing litharge $(\mathrm{PbO})$, activated carbon (C), sodium carbonate $\left(\mathrm{Na}_{2} \mathrm{CO}_{3}\right)$, sodium hydroxide $(\mathrm{NaOH})$, silica $\left(\mathrm{SiO}_{2}\right)$, borax $\left(\mathrm{Na}_{2} \mathrm{~B}_{4} \mathrm{O}_{7}\right.$, anhydrous), and this mixture was fused in air at $1200{ }^{\circ} \mathrm{C}$ for $15 \mathrm{~min}$ after dosing the mixture into a preheated fire clay crucible. The lead and slag fractions were separated from one another, whereby the molten lead fraction was cast in a water-cooled mould under $\mathrm{N}_{2}$ atmosphere. The surface of the cylindrical $\mathrm{Pb}$ buttons thus obtained (diameter: $25 \mathrm{~mm}$, thickness: $7-10 \mathrm{~mm}$, mass $\approx 50 \mathrm{~g}$ ) was further treated using a HNFF high speed milling machine (Herzog, Germany) to 
obtain flat, polished surfaces. The SARM buttons were prepared in duplicate.

\section{Instrumentation}

A chirped pulse amplification (CPA)-type Ti-sapphire-based laser system operated at a wavelength of $795 \mathrm{~nm}$ (Legend, Coherent Inc., Santa Clara, CA, USA) was used to generate pulses of $<150 \mathrm{fs}$ duration with a variable repetition rate up to $1 \mathrm{kHz}$ and approximately $2.4 \mathrm{~mJ}$ output energy. The pulse duration was derived from the full width at half maximum (FWHM) of the spectrum emitted by the amplified laser radiation, assuming the pulse to be Fourier-limited. The radiation was delivered to the ablation site via dielectric mirrors and focused onto the sample surface using a plano-convex, UV-grade quartz lens of $50 \mathrm{~mm}$ focal length. For sample observation, a CCD camera equipped with a macro-objective of variable magnification $(0.8-4.0)$ was installed. The optical paths of observation and beam delivery system were separated allowing for an independent adjustment of spot size and vertical sample position.

The ablation chamber $(\mathrm{L} \times \mathrm{B} \times \mathrm{D}: 450 \mathrm{~mm} \times 70 \mathrm{~mm} \times$ $40 \mathrm{~mm}$ ) constructed in-house (ETH-Zürich) hosts up to $10 \mathrm{~Pb}$ buttons and separates sample volume and effective vaporization volume (Fig. 1), thus providing an excellent behavior in terms of analyte transport efficiency, signal tailing and memory effects.

A PerkinElmer Sciex Elan DRCII quadrupole-based ICP-MS unit, equipped with a dynamic reaction cell (DRC), was used for signal acquisition. As in previous works, ${ }^{11,12}$ the spectral interferences resulting from the occurrence of $\mathrm{Pb}^{2+}$ ions were counteracted by pressurizing the dynamic reaction cell (DRC) with

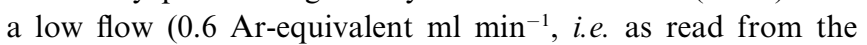
instrument's mass flow controller which is calibrated for Ar) of $\mathrm{NH}_{3}$ as a reaction gas. As the first ionization energy of $\mathrm{NH}_{3}$ $(10.16 \mathrm{eV})$ is between the first ionization energy of the PGMs (for the most affected element Rh: $7.46 \mathrm{eV}$ ) and the second ionization energy for $\mathrm{Pb}(15.03 \mathrm{eV}),{ }^{33}$ this reaction gas is capable of selectively transferring an electron to $\mathrm{Pb}^{2+}$. In the previous works referred to, it was also shown that the determination of the other PGMs of interest did not suffer from the use of $\mathrm{NH}_{3}$ as a reaction gas. In fact, the collisional focusing resulting from the use of the reaction gas, even enhanced the sensitivity to some extent. Only for Ir, a decrease in the signal-to-blank ratio was observed because of formation of adduct ions. According to Bohme, ${ }^{34}$ the

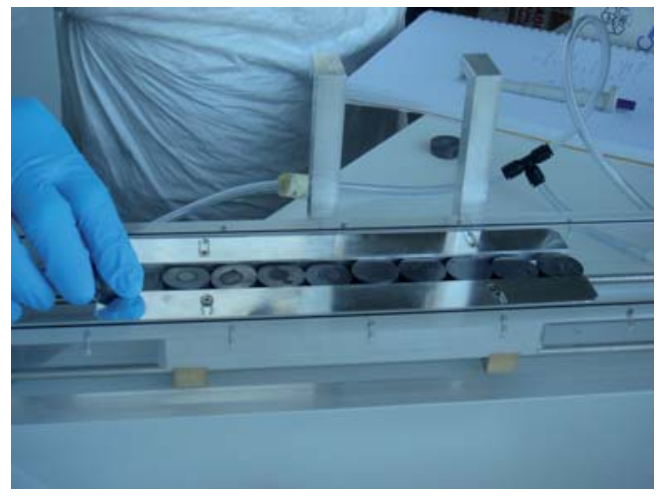

Fig. 1 Loading of $\mathrm{Pb}$ fire assay buttons into a sample chamber capable of housing a maximum of ten buttons.
Table 1 Instrument settings and data acquisition parameters used for femtosecond LA-ICP-MS analysis of $\mathrm{Pb}$ buttons produced by fire assay of platiniferous ores

\begin{tabular}{|c|c|}
\hline \multicolumn{2}{|c|}{ Laser ablation characteristics and settings } \\
\hline Wavelength & $795 \mathrm{~nm}$ \\
\hline Pulse duration & $150 \mathrm{fs}$ \\
\hline Energy & $2.4 \mathrm{~mJ}$ \\
\hline Repetition rate & $20 \mathrm{~Hz}$ \\
\hline Beam diameter & $150 \mu \mathrm{m}$ \\
\hline \multicolumn{2}{|c|}{ ICP-mass spectrometer characteristics and settings } \\
\hline \multicolumn{2}{|l|}{ Perkin Elmer Sciex Elan DRCII } \\
\hline Rf power & $1200 \mathrm{~W}$ \\
\hline \multicolumn{2}{|l|}{ Gas flow rates } \\
\hline Plasma & 18.0 \\
\hline Auxiliary & 0.8 \\
\hline Carrier & $\begin{array}{l}0.6 \mathrm{~L} \mathrm{~min}^{-1} \mathrm{Ar} \text { (cell) plus } \\
0.45 \mathrm{~L} \mathrm{~min}^{-1} \mathrm{Ar} \text { (after cell) }\end{array}$ \\
\hline Extraction lens voltage & $7 \mathrm{~V}$ \\
\hline Reaction gas and flow rate & $\mathrm{NH}_{3}, 0.60$ Ar-equivalent $\mathrm{mL} \mathrm{min}^{-1}$ \\
\hline RPQ setting & 0.35 \\
\hline RPa setting & 0.00 \\
\hline QRO & $-8 \mathrm{~V}$ \\
\hline $\mathrm{CRO}$ & $-3 \mathrm{~V}$ \\
\hline $\mathrm{CPV}$ & $-15 \mathrm{~V}$ \\
\hline \multicolumn{2}{|c|}{ ICP-MS data acquisition parameters } \\
\hline Scanning mode & Peak hopping \\
\hline Dwell time per acquisition point & $10 \mathrm{~ms}$ \\
\hline Pre-integration time & $10 \mathrm{~s}$ \\
\hline Integration window & $40 \mathrm{~s}$ \\
\hline Nuclides monitored & 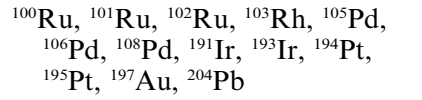 \\
\hline Detector mode & Dual-pulse counting and analog \\
\hline
\end{tabular}

reaction between $\mathrm{Ir}$ and $\mathrm{NH}_{3}$ is resulting in $\mathrm{IrNH}_{2}{ }^{+}$and $\mathrm{IrNH}_{2}{ }^{+}\left(\mathrm{NH}_{3}\right)_{0-4}$ as reaction products. However, even for Ir, simultaneous determination with the other PGMs remained possible.

The ICP-MS settings used throughout this work are summarized in Table 1.

\section{Measurements and quantification approach}

For all four of the SARMs considered, two buttons were analyzed under the conditions evaluated as most adequate upon systematic study. For each blank, standard or sample button, single hole drilling was applied on 5 separate locations during a time interval of typically $60 \mathrm{~s}$. The first $10 \mathrm{~s}$ were discarded, both for reasons of signal stabilization and for avoiding a negative effect from potential surface enrichment-vide infra. The signal intensity integrated over the next $40 \mathrm{~s}$ was relied upon for quantification purposes. The gas blank was monitored, but was observed to be negligible in all instances $(<2 \%$ even for the samples/standards with the lowest PGM concentrations). Due to single hole drilling analysis on 5 different locations, measurement of a single button takes approximately 10-15 min. Despite the fact that a set comprising 10 standards was available, in each instance the calibration curve was constructed on the basis of the results of the blank and 4 standards, spanning a range of signal intensities around that displayed by the sample. Deploying the intensity of the ${ }^{204} \mathrm{~Pb}^{+}$signal as an internal reference was observed to have a beneficial effect on the quality of the results obtained (vide infra) and was used throughout this work. A typical signal profile is given in Fig. 2. This profile illustrates the co-evolution 


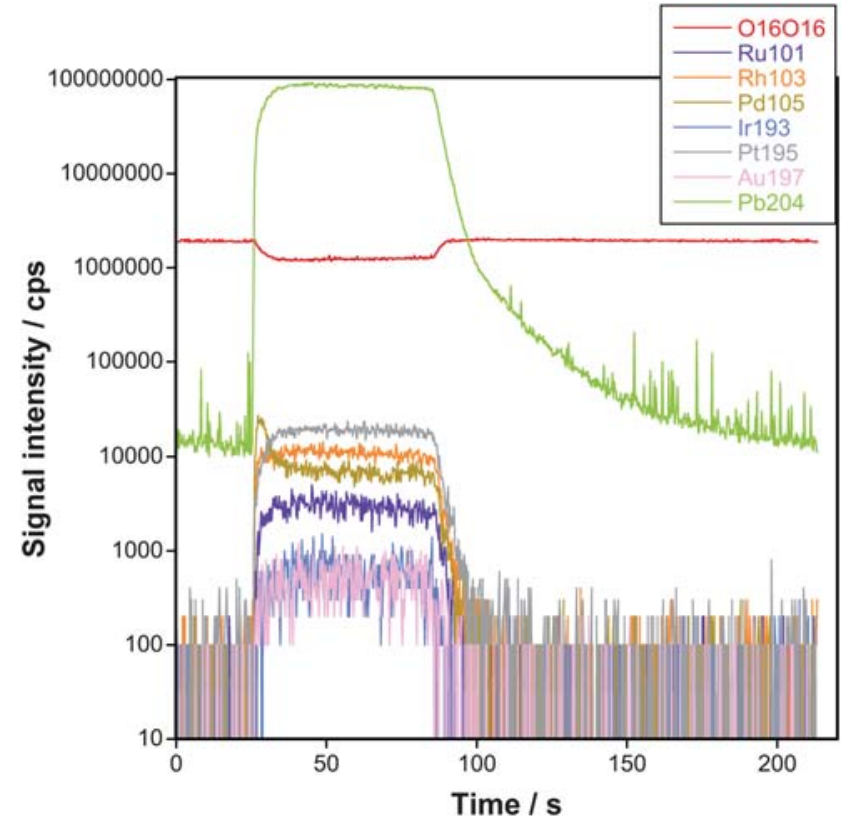

Fig. 2 Typical signal profile observed upon femtosecond LA-ICP-MS ablation of a fire-assay $\mathrm{Pb}$ button. Although for quality control purposes, two nuclides of each target element were monitored (wherever possible), the signal for only one nuclide was shown for reasons of clarity. Next to the signal intensities for the target elements, also the signals for ${ }^{204} \mathrm{~Pb}^{+}$ (internal reference) and ${ }^{16} \mathrm{O}_{2}{ }^{+}$(indicator of signal suppression) are depicted. The ${ }^{105} \mathrm{Pd}^{+}$signal testifies of Pd surface enhancement (PGM concentrations in the $\mathrm{Pb}$ button: $\mathrm{Rh}: 2.13 \mu \mathrm{g} \mathrm{g}^{-1}, \mathrm{Pd}: 6.23 \mu \mathrm{g} \mathrm{g}^{-1}$, Ru: $3.04 \mu \mathrm{g} \mathrm{g}^{-1}$, Ir: $0.63 \mu \mathrm{g} \mathrm{g}^{-1}$, Pt: $11.77 \mu \mathrm{g} \mathrm{g}^{-1}$ and $\mathrm{Au}: 0.09 \mu \mathrm{g} \mathrm{g}^{-1}$ ).

of the signal intensity of ${ }^{204} \mathrm{~Pb}^{+}$and those of most of the PGMs (see Table 1 for nuclides monitored). For Pd, surface enrichment was observed. This phenomenon was investigated in more detail and will be discussed below. In this specific case, the signal intensity of the ${ }^{16} \mathrm{O}_{2}{ }^{+}$signal serves as an indication of plasma loading and the signal suppression it gives rise to. This signal profile also serves as an illustration of the excellent 'washout behavior' demonstrated by the ablation cell. After ablation has ceased, the signal intensities for both the target elements and the matrix element return to their original gas blank values. A systematic increase in the ${ }^{204} \mathrm{~Pb}$ blank signal throughout a series of 5 consecutive measurements of a single $\mathrm{Pb}$ button or throughout a measurement day was never observed. In fact, within seconds after ablation had stopped, the ${ }^{204} \mathrm{~Pb}$ signal intensity decreased by three orders of magnitude, thus, contributing less than $0.1 \%$ to the signal intensity of the subsequent sample already at that stage. Self-evidently however, the build-up of sample material on the window of the ablation chamber will prevent the chamber to be used in the context of trace $\mathrm{Pb}$ determination without prior cleaning.

\section{Results and discussion}

\section{Evaluation of crater shape}

A first evaluation of the ablation behavior of a soft, low-melting and volatile metal as $\mathrm{Pb}\left(\mathrm{MP}: 327.5^{\circ} \mathrm{C}\right.$, BP: $\left.1740.0^{\circ} \mathrm{C}^{33}\right)$ with the experimental set-up used, was based on SEM images of the
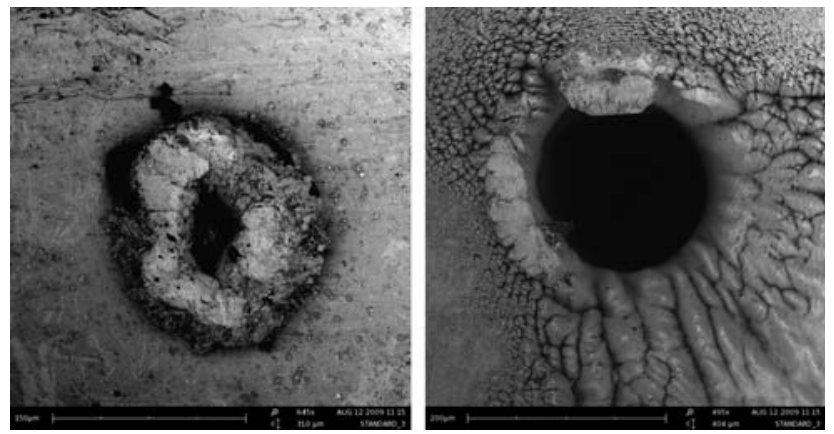

Fig. 3 SEM images of LA craters in $\mathrm{Pb}(<99 \%)$ buttons obtained using (left) an $\mathrm{ArF}^{*}$ excimer LA system $(193 \mathrm{~nm}, 20 \mathrm{~ns}$ pulse duration, E: $2.5 \mathrm{~mJ}$, beam diameter: $120 \mu \mathrm{m}$, repetition rate: $20 \mathrm{~Hz}, 300$ shots) and (right) a femtosecond LA system (795 nm, 150 fs pulse duration, E: $2.5 \mathrm{~mJ}$, beam diameter: $150 \mu \mathrm{m}$, repetition rate: $20 \mathrm{~Hz}, 1000$ shots).

sample surface after ablation. Fig. 3 provides visual evidence that also for $a>99 \% \mathrm{~Pb}$ matrix, the LA craters obtained are better defined with the fs-LA system used in this study than with the nsLA system used in previous work. Despite this improved crater formation, Fig. 3 also demonstrates that due to the specific characteristics of $\mathrm{Pb}$, melting was not completely avoided.

\section{Selection of an internal standard}

Next, efforts were focused on selecting an appropriate internal standard for correcting for variations in the ablation and transport efficiencies and in the sensitivity of the ICP-MS instrument. It is common practice to select a minor isotope of a matrix element of known concentration for this purpose. Since the signal intensities observed for ${ }^{204} \mathrm{~Pb}^{+}$are extremely high compared to those typical for the target elements studied in this project, the use of the ${ }^{204} \mathrm{~Pb}^{16} \mathrm{O}^{+}$as an internal reference signal was also considered as it shows an intensity similar to that of the target nuclides. However, the continuous decrease in the ${ }^{204} \mathrm{~Pb}^{16} \mathrm{O}^{+}$signal intensity observed throughout the course of one of the measurement sessions - in contrast to the fairly stable signal intensity observed for ${ }^{204} \mathrm{~Pb}^{+}$-indicated that this is not a viable approach (Fig. 4). Most probably, the continuous decrease in $\mathrm{PbO}^{+}$intensity observed is due to the presence of residual humidity at the start of the measurement session, a circumstance that can be encountered more often if both pneumatic nebulization and laser ablation are used in combination with the same ICP-MS unit. The advantage brought by using the signal of ${ }^{204} \mathrm{~Pb}^{+}$as an internal standard can be illustrated by means of the effect it has on the calibration curve for $\mathrm{Au}$, constructed on the basis of the measurement results for a set of 6 standards (blank, 0.1, 0.2, 0.3, 0.4 and $0.6 \mu \mathrm{g} \mathrm{g}^{-1}$ ). The measurements and calculation of the corresponding calibration curve were carried out four times on different days. As a result of the stability of the LA-ICP-MS setup used, the effect of using an internal standard on the linearity was insignificant at the $95 \%$ confidence level and the average linear correlation coefficient $r^{2}$ was improved from 0.991 to 0.994 only. However, when not using the ${ }^{204} \mathrm{~Pb}^{+}$signal as an internal reference, the slopes of the calibration curves showed a variation of $\sim 14 \%$ as compared to a variation of $\sim 4 \%$ only, when normalizing all signals using the 


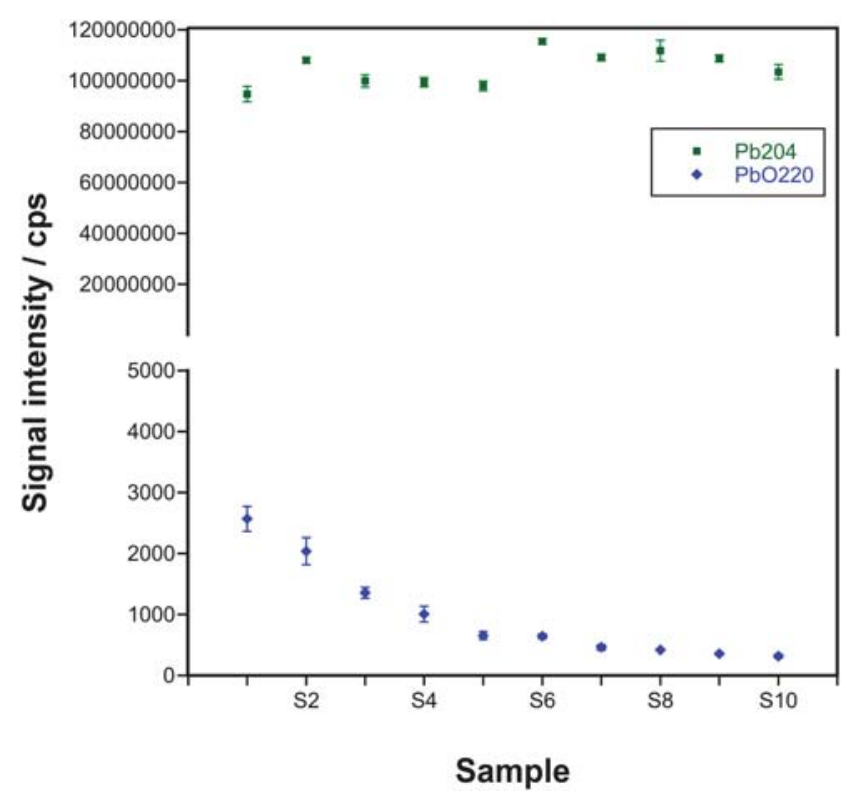

Fig. 4 Variations of signal intensities for ${ }^{204} \mathrm{~Pb}^{+}$and ${ }^{204} \mathrm{PbO}^{+}$(potential internal reference signals) during the course of a measurement session. Error bars represent standard deviations $(\mathrm{N}=5)$.

${ }^{204} \mathrm{~Pb}^{+}$signal intensity. This indicates that the analyte transport and ionization efficiencies for all materials analyzed were stable within $14 \%$.

\section{Selection of carrier gas}

It is well-known that when using He instead of $\mathrm{Ar}$ as a carrier gas, the plume of sample material created upon impact of the laser beam can expand more freely, whereby re-deposition of material on the sample surface is avoided to a large extent and the sample introduction efficiency into the ICP and thus, the signal intensity is enhanced. ${ }^{35,36}$ For studying the influence of the carrier gas, the conditions were changed such that an approximately constant flow of material into the ICP was obtained. This was realized by decreasing the laser energy correspondingly upon increasing the laser repetition frequency at a constant beam diameter. The corresponding results (first three rows for each combination of carrier and make-up gas, admixed post-ablation, in Table 2), show no major changes. The fourth row displays the LODs obtained by combining maximum laser energy, repetition rate and beam diameter and thus, a substantially higher mass flow rate of sample aerosol into the ICP. The LODs obtained in this way however are not substantially better than those obtained at a more modest sample introduction rate, which is at least partly to be attributed to the signal suppression demonstrated to occur under these high sample aerosol mass flow rates (see next paragraph). The most important conclusion to be drawn from Table 2 is that in this particular context, the gain in LOD when using $\mathrm{He}$ instead of $\mathrm{Ar}$ as the carrier gas is negligible. $\mathrm{As} \mathrm{Pb}$ was observed to be deposited at a much faster rate on the ablation window when using $\mathrm{He}$ as a carrier gas ( $c f$. the aforementioned the expansion of the plume), Ar was selected for all further work.

\section{Study of loading effects}

The effect of the introduction of the LA aerosol into the ICPfurther referred to as loading effect - was studied by monitoring a signal expected to remain constant in the absence of matrix effects. Several signals - for example ${ }^{16} \mathrm{O}_{2}{ }^{+},{ }^{38} \mathrm{Ar}^{+}$and ${ }^{40} \mathrm{Ar}_{2}{ }^{+}-$ were observed to be fit-for-purpose and from this set, ${ }^{38} \mathrm{Ar}^{+}$was selected for further plasma studies. The effect of increasing the amount of material introduced per unit of time into the ICP on the ${ }^{38} \mathrm{Ar}^{+}$signal intensity is shown in Fig. 5, in which also the effect on one of the target nuclides $\left({ }^{196} \mathrm{Pt}^{+}\right)$is depicted. It is visible that at every energy level, the ${ }^{38} \mathrm{Ar}^{+}$signal intensity is decreased upon increasing the laser repetition frequency. The higher the laser energy, the more pronounced the suppression observed for the ${ }^{38} \mathrm{Ar}^{+}$signal upon increasing the laser repetition frequency from 10 to 20 and eventually to $40 \mathrm{~Hz}$. The signal suppression demonstrated in this way limits the increase in the analyte signal intensities (represented here by the ${ }^{196} \mathrm{Pt}^{+}$signal intensity) observed upon enhancing the repetition rate and thus, the mass flow of sample aerosol into the ICP. At a laser energy of $2.5 \mathrm{~mJ}$, e.g., the increase in ${ }^{196} \mathrm{Pt}^{+}$signal intensity observed upon increasing the laser repetition rate from 10 to $40 \mathrm{~Hz}$ is less than two, as opposed to the theoretically expected factor of $4 .{ }^{37}$ Also when the carrier gas flow rate was optimized for each set of conditions, the increase in signal intensity theoretically expected upon increasing the repetition frequency could not be realized,

Table 2 Preliminary ${ }^{a}$ limits of detection (in $\mu \mathrm{g} \mathrm{g}^{-1}$ ) as obtained using various combinations of carrier gas (swept through the ablation chamber) and make-up gas (admixed post-ablation)

\begin{tabular}{|c|c|c|c|c|}
\hline $\begin{array}{l}\text { Conditions (repetition rate - laser } \\
\text { energy - beam diameter) }\end{array}$ & $\mathrm{Rh} v i a^{103} \mathrm{Rh}$ & $\mathrm{Pd}$ via ${ }^{105} \mathrm{Pd}$ & Pt via ${ }^{194} \mathrm{Pt}$ & $\mathrm{Au}$ vic \\
\hline \multicolumn{5}{|c|}{$\mathrm{He}$ as carrier gas, mixed with Ar post-ablation } \\
\hline $10 \mathrm{~Hz}-1.5 \mathrm{~mJ}-150 \mu \mathrm{m}$ & 0.014 & 0.011 & 0.059 & 0.034 \\
\hline $20 \mathrm{~Hz}-0.75 \mathrm{~mJ}-150 \mu \mathrm{m}$ & 0.011 & 0.032 & 0.048 & 0.029 \\
\hline $40 \mathrm{~Hz}-0.375 \mathrm{~mJ}-150 \mu \mathrm{m}$ & 0.021 & 0.045 & 0.064 & 0.048 \\
\hline $40 \mathrm{~Hz}-1.5 \mathrm{~mJ}-500 \mu \mathrm{m}$ & 0.009 & 0.039 & 0.037 & 0.011 \\
\hline \multicolumn{5}{|c|}{ Ar as carrier gas, mixed with He post-ablation } \\
\hline $10 \mathrm{~Hz}-1.5 \mathrm{~mJ}-150 \mu \mathrm{m}$ & 0.019 & 0.030 & 0.039 & 0.019 \\
\hline $20 \mathrm{~Hz}-0.75 \mathrm{~mJ}-150 \mu \mathrm{m}$ & 0.033 & 0.183 & 0.048 & 0.047 \\
\hline $40 \mathrm{~Hz}-0.375 \mathrm{~mJ}-150 \mu \mathrm{m}$ & 0.038 & 0.081 & 0.089 & 0.046 \\
\hline $40 \mathrm{~Hz}-1.5 \mathrm{~mJ}-500 \mu \mathrm{m}$ & 0.017 & 0.059 & 0.035 & 0.010 \\
\hline
\end{tabular}

${ }^{a}$ The LODs reported in Table 2 are obtained under different conditions than those assessed as most adequate for analysis (see Table 1). The LODs reported in Table 2 and 3, respectively, should thus not be directly compared. 


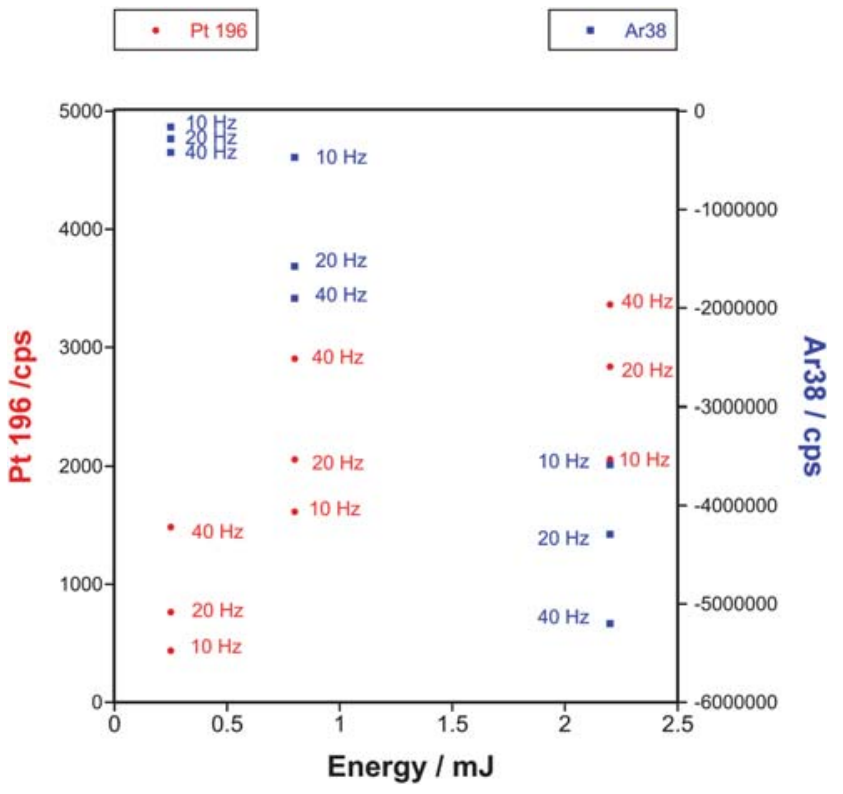

Fig. 5 Investigation of loading effects by plotting the signals for ${ }^{38} \mathrm{Ar}^{+}$ (as a proxy for signal suppression-right $y$-axis) and ${ }^{196} \mathrm{Pt}^{+}$(as an indication of instrument sensitivity-left axis) as a function of the laser energy at three repetition rates.

which confirms that the enhanced plasma loading gives rise to a genuine suppression rather than a mere shift in the zones of maximum $\mathrm{M}^{+}$density. ${ }^{38}$ Inspired by earlier work reporting on an enhanced plasma robustness upon wetting (co-introduction of nebulized water ${ }^{39}$ ), it was evaluated whether this would mitigate the pronounced signal suppression seen when introducing $\mathrm{Pb}$ as a matrix into the ICP. However, also under these conditions, matrix-induced suppression was observed to approximately the same extent.

In the specific case of this application however, a blank (a pure $\mathrm{Pb}$ button) and matrix-matched standards were available and deployed for quantification purposes, such that the signal suppression could be easily compensated for.

\section{Sample heterogeneity}

Although at one stage, the entire sample was liquid and could therefore be expected to be sufficiently homogeneous, surface enrichment has been reported before for some target elements ${ }^{40}$ and therefore, attention was paid to this phenomenon, especially as the occurrence of surface enrichment would influence the results obtained much more seriously in the case of line scanning or rastering than in the case of single hole drilling. In order to study the surface enrichment systematically, one sample button and one standard button were ablated according to successive scan lines. At the estimated level of sample removal of $5 \mu \mathrm{m}$ shot $^{-1}$ under the condition used, this corresponds to a sampling depth of $100 \mu \mathrm{m}$ for each raster line. Fig. 6a is evidence for a slight enrichment of $\mathrm{Pd}$ at the surface of the $\mathrm{Pb}$ button investigated. Although from the ${ }^{105} \mathrm{Pd} /{ }^{204} \mathrm{~Pb}$ signal ratio itself (red line), it could be deduced that already with the second raster line, the "bulk" of the button material wherein Pd is homogeneously distributed is reached, this does not yet give origin to an accurate
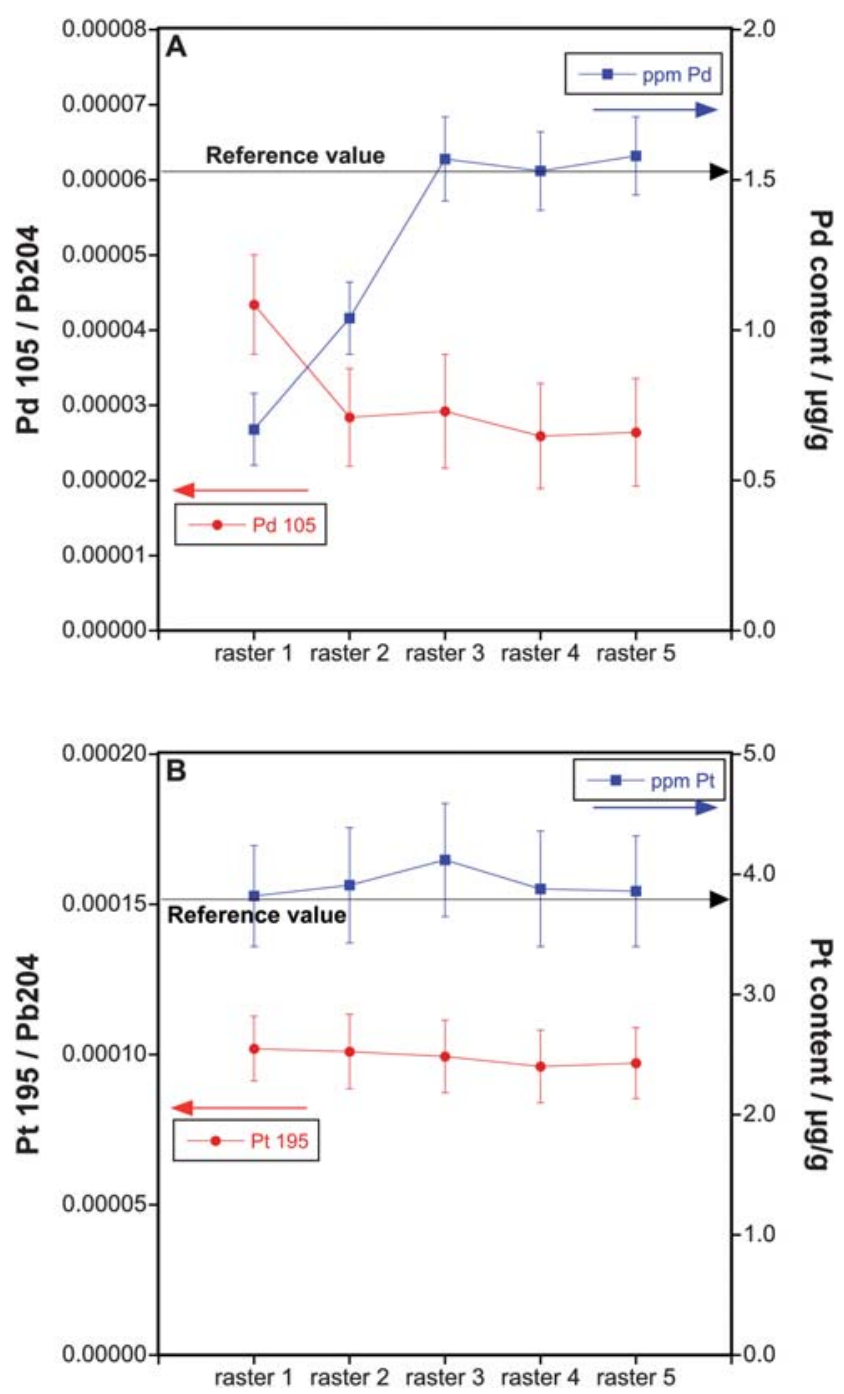

Fig. 6 a. (upper figure) ${ }^{105} \mathrm{Pd}^{+}$signal intensity and $\mathrm{Pd}$ concentration determined as a function of the penetration depth into the $\mathrm{Pb}$ button and b. (lower figure) ${ }^{195} \mathrm{Pt}^{+}$signal intensity and $\mathrm{Pt}$ concentration determined as a function of the penetration depth into the $\mathrm{Pb}$ button $(E=2.4 \mathrm{~mJ}$, beam diameter: $150 \mu \mathrm{m}$ diameter, repetition rate: $20 \mathrm{~Hz}$, lateral rastering speed $150 \mu \mathrm{m} \mathrm{s}^{-1}, E=2.4 \mathrm{~mJ}$ ). Error bars represent standard deviations.

analysis result (blue line). This is the result of a more pronounced heterogeneity of the Pd distribution in the standard button, i.e. occurring until a larger depth under the surface ( $2^{\text {nd }}$ raster line). As of the third raster line, the corresponding result is representative for the bulk composition. These observations were confirmed by drilling experiments, demonstrating that the region of surface enrichment sometimes observed was surpassed after a maximum of 20 (samples) to 40 (standards) shots. As a result, the 'drilling' sampling approach whereby the laser is continuously fired at one sample location during $60 \mathrm{~s}$ should provide reliable results, as (i) the material sampled predominantly comes from locations deeper below the surface, while the first fraction of the signal (partly corresponding to the area suffering from enrichment) is discarded anyway (corresponding to the first $10 \mathrm{~s}$ of ablation). Alternatively, analysis could be performed on a freshly milled surface of the sample as this pre-concentration 
effect is time-dependent. Earlier (non-published) work carried out at Anglo Research has demonstrated that it usually takes about 4-8 h before the change in intensity/concentration becomes statistically significant. Fig. $6 \mathrm{~b}$, on the other hand, demonstrates that this phenomenon of surface enrichment is also clearly element-dependent, as for the same pair of sample and standard buttons, no effect whatsoever on either the ${ }^{195} \mathrm{Pt}^{+}$signal intensity, nor the Pt concentration obtained could be observed. Throughout the course of this study, surface enrichment was sometimes observed for Pd and, to a lesser extent, also for $\mathrm{Au}$ and Rh. Surface enrichment was observed to a higher extent for the standard than for sample buttons. Possibly, the mobility of $\mathrm{Pd}$ (and the other elements affected) in the lead is dependent on the alloy composition and the small quantities of $\mathrm{Ni}, \mathrm{Cu}$ and $\mathrm{S}$ that sample buttons often contain, seem to reduce this phenomenon.

\section{Sensitivity and limits of detection (LODs)}

The sensitivity obtained under the conditions summarized in Table 1 ranges from $\sim 4000 \mathrm{cps}$ per $\mu \mathrm{g} \mathrm{g}^{-1}$ for the lighter PGMs to $\sim 7000 \mathrm{cps}$ per $\mu \mathrm{g} \mathrm{g}^{-1}$ for the heavier ones. Only Ir shows a lower sensitivity $\left(\sim 2000\right.$ cps per $\left.\mu \mathrm{g} \mathrm{g}^{-1}\right)$ due to its reactivity towards $\mathrm{NH}_{3}$, leading to the formation of adduct ions. More important than the sensitivities, however, are the LODs. These were determined according to IUPAC's 3s-crtiterion, ${ }^{41}$ whereby a pure $\mathrm{Pb}$ button (no PGMs added) was used as a blank. The LODs thus obtained are summarized in Table 3, wherein also the LODs as obtained using nanosecond LA-ICP-MS and presented in a previous work ${ }^{\mathbf{1 2}}$ have been included for comparison. When using fs LA-ICP-MS, the LODs range from 0.003 to $0.015 \mu \mathrm{g} \mathrm{g}^{-1}$, resulting in an improvement with a factor of 3 to 10 when compared to the values for ns LA-ICP-MS. It can be pointed out that while with ns LA-ICP-MS, the diameter of the laser beam was $120 \mu \mathrm{m}$, that used with the fs LA-ICP-MS instrumentation was $150 \mu \mathrm{m}$, while there is also a pronounced difference in integration time and sample consumption-10 s for ns LA-ICPMS versus $40 \mathrm{~s}$ for fs LA-ICP-MS. Unfortunately, the exact amount of sample consumed in both instances cannot be accurately determined - in the case of ns LA-ICP-MS, the melting effects (Fig. 3) prevented not only a longer integration time, but also any meaningful estimation of the crater depth, while in the case of fs LA-ICP-MS, the craters are too deep for depth determination using profilometry. Only the initial penetration depth per shot could be quantified and turned out to be $5 \mu \mathrm{m}$ shot $^{-1}$, but this is known to decrease rapidly at greater depth. The improvement in sensitivity and detection power that the fs LAICP-MS set-up shows with respect to its ns LA-ICP-MS counterpart, most probably has to be attributed to a higher analyte introduction efficiency into the ICP and a particle size distribution, shifted to smaller diameters. Although not extremely spectacular, the enhancement in detection power displayed by fs LA-ICP-MS is very important as it enabled the determination of Au and Ir in some samples, which could not be realized via ns LA-ICP-MS. The fs LA-ICP-MS LODs are even slightly better than those reported for glow discharge (GD)sector-field MS, despite the considerably larger sample consumption in the case of GD sputtering $(8.2 \mathrm{~mm}$ crater diameter). ${ }^{12}$

\section{Evaluation of the quantitative analysis data}

The quantitative results obtained upon analysis of the $\mathrm{Pb}$ buttons prepared from 4 reference materials using fs-LA-ICP-MS under the conditions summarized in Table 1 and relying on a calibration curve constructed using the data for matrix-matched

Table 3 Limits of detection (in $\mu \mathrm{g} \mathrm{g}^{-1}$ ) for the determination of PGMs and Au in Pb buttons via nanosecond LA-ICP-MS ${ }^{12}$ and femtosecond LA-ICPMS (this work, under the conditions summarized in Table 1), respectively, and the improvement observed upon using the latter type of instrumental set-up

\begin{tabular}{llllll}
\hline LODs/ $\mu \mathrm{g} \mathrm{g}^{-1}$ & $\mathrm{Rh}$ & $\mathrm{Pd}$ & $\mathrm{Ru}$ & $\mathrm{Ir}$ & $\mathrm{Pt}$ \\
\hline Nanosecond LA-ICP-MS & 0.020 & 0.030 & 0.035 & 0.050 & 0.025 \\
Femtosecond LA-ICP-MS & 0.003 & 0.009 & 0.012 & 0.015 & 0.006 \\
Enhancement factor & 6.7 & 3.3 & 2.9 & 3.3 & 4.2 \\
\hline
\end{tabular}

Table 4 Femtosecond LA-ICP-MS results $\left(\mu \mathrm{g} \mathrm{g}^{-1}\right)$ for Pb buttons obtained via fire assay of four platiniferous ore reference materials (SARMs $7 \mathrm{~b}$, 64, 65 and 66) with the corresponding standard deviation (for $\mathrm{N}=5$ )

\begin{tabular}{|c|c|c|c|c|c|c|c|}
\hline & Value & $\mathrm{Rh}$ & $\mathrm{Pd}$ & $\mathrm{Ru}$ & $\operatorname{Ir}^{*}$ & $\mathrm{Pt}$ & $\mathrm{Au}^{\dagger}$ \\
\hline \multirow[t]{2}{*}{ SARM7b } & LA-ICP-MS button 1 & $0.245 \pm 0.009$ & $1.73 \pm 0.20$ & $0.448 \pm 0.033$ & $0.081 \pm 0.003$ & $3.66 \pm 0.18$ & $0.227 \pm 0.006$ \\
\hline & LA-ICP-MS button 2 & $0.237 \pm 0.015$ & $1.47 \pm 0.18$ & $0.441 \pm 0.065$ & $0.102 \pm 0.007$ & $3.65 \pm 0.06$ & $0.236 \pm 0.010$ \\
\hline \multirow[t]{3}{*}{ SARM64 } & LA-ICP-MS button 1 & $0.082 \pm 0.005$ & $0.184 \pm 0.013$ & $0.233 \pm 0.021$ & $0.039 \pm 0.004$ & $0.445 \pm 0.020$ & $0.022 \pm 0.001$ \\
\hline & LA-ICP-MS button 2 & $0.084 \pm 0.004$ & $0.192 \pm 0.017$ & $0.235 \pm 0.010$ & $0.035 \pm 0.005$ & $0.462 \pm 0.021$ & $0.019 \pm 0.001$ \\
\hline & reference value & $0.080 \pm 0.005$ & $0.210 \pm 0.015$ & $0.240 \pm 0.015$ & $0.052 \pm 0.005$ & $0.475 \pm 0.013$ & $0.018 \pm 0.003$ \\
\hline SARM65 & LA-ICP-MS button 1 & $0.518 \pm 0.041$ & $1.16 \pm 0.12$ & $0.825 \pm 0.061$ & $0.166 \pm 0.012$ & $2.70 \pm 0.07$ & $0.034 \pm 0.002$ \\
\hline \multirow[t]{3}{*}{ SARM66 } & LA-ICP-MS button 1 & $16.3 \pm 2.3$ & $52.5 \pm 7.8$ & $25.9 \pm 3.0$ & $4.29 \pm 0.06$ & $85.9 \pm 2.2$ & $0.872 \pm 0.042$ \\
\hline & LA-ICP-MS button 2 & $17.6 \pm 1.4$ & $52.0 \pm 5.6$ & $28.7 \pm 4.9$ & $4.05 \pm 0.19$ & $88.8 \pm 10.1$ & $0.845 \pm 0.042$ \\
\hline & reference value & $17.5 \pm 1.8$ & $51.1 \pm 4.7$ & $26.5 \pm 1.5$ & $7.1 \pm 2.2$ & $91.2 \pm 3.2$ & $0.660 \pm 0.030$ \\
\hline
\end{tabular}


Table 5 A comparison of the figures of merit obtained upon quantitative analysis of $\mathrm{Pb}$ buttons obtained via fire assay of four platiniferous ore reference materials (SARMs 7b, 64, 65 and 66) using (i) femtosecond LA-ICP-MS and (ii) nanosecond LA-ICP-MS. ${ }^{12}$ Indicated in the table are: (i) the fraction of the results showing overlap with the certified range, (ii) the fraction of the results showing a bias $<5,10$ and $20 \%$, respectively, with respect to the corresponding reference value, (iii) the average bias between the LA-ICP-MS result and the corresponding certified value and (iv) the standard deviation of the observed biases

\begin{tabular}{|c|c|c|c|c|c|}
\hline FEMTOSECOND LA-ICP-MS & $\mathrm{Rh}$ & $\mathrm{Pd}$ & $\mathrm{Ru}$ & $\mathrm{Pt}$ & $\mathrm{Au}^{a}$ \\
\hline Overlap of uncertainty ranges & $8 / 8$ & $8 / 8$ & $7 / 8$ & $8 / 8$ & $4 / 6$ \\
\hline Results within $5 \%$ & $7 / 8$ & $4 / 8$ & $6 / 8$ & $6 / 8$ & $1 / 6$ \\
\hline Results within $20 \%$ & $8 / 8$ & $8 / 8$ & $8 / 8$ & $8 / 8$ & $5 / 6$ \\
\hline Average bias $(\%)$ & +0.4 & -2.1 & +0.3 & -2.4 & -1.6 \\
\hline St. dev. (biases) & 3.5 & 9.6 & 6.1 & 2.9 & 14.1 \\
\hline Overlap of uncertainty ranges & $6 / 8$ & $6 / 8$ & $6 / 8$ & $7 / 8$ & $2 / 2$ \\
\hline Results within $5 \%$ & $2 / 8$ & $5 / 8$ & $2 / 8$ & $6 / 8$ & $1 / 2$ \\
\hline Results within $10 \%$ & $5 / 8$ & $7 / 8$ & $2 / 8$ & $7 / 8$ & $2 / 2$ \\
\hline Results within $20 \%$ & $7 / 8$ & $7 / 8$ & $4 / 8$ & $8 / 8$ & $2 / 2$ \\
\hline Average bias (\%) & +4.4 & +4.8 & -25 & +3.8 & -5.0 \\
\hline St. dev. (biases) & 12.9 & 7.7 & 10.5 & 4.1 & 2.8 \\
\hline
\end{tabular}

standards are summarized in Table 4. Also the corresponding certified values are indicated. Table 5 provides an in-depth evaluation of the analysis results thus obtained and permits comparison to the values reported earlier for ns LA-ICP-MS.

For $\mathrm{Rh}, \mathrm{Pd}, \mathrm{Ru}$ and $\mathrm{Pt}$, all experimental results agree within $20 \%$ of the corresponding certified value. For $\mathrm{Rh}$, the agreement between the experimental results and the corresponding values is even better-with a deviation in all cases $<10 \%$ and in all but one case even $<5 \%$. This confirms that the spectral interference caused by the occurrence of $\mathrm{Pb}^{2+}$ ions and hindering $\mathrm{Rh}$ determination with a vented cell is successfully overcome and its influence removed, which is remarkable, given the backgroundequivalent concentration of $2.1 \mu \mathrm{g} \mathrm{g}^{-1}$ for $\mathrm{Rh}$ at an $\mathrm{m} / \mathrm{z}$ of 103 under vented conditions. For both $\mathrm{Pt}$ and $\mathrm{Ru}$, the results obtained can be considered as excellent with a bias $<10 \%$ for $\mathrm{Pt}$ in all cases and in all but one case for $\mathrm{Ru}$. The determination of $\mathrm{Ru}$ via monitoring of the ${ }^{102} \mathrm{Ru}^{+}$is also affected by spectral interference under vented conditions (leading to a BEC of $0.4 \mu \mathrm{g} \mathrm{g}^{-1}$ ). However, pressurizing the reaction cell with $\mathrm{NH}_{3}$ also renders this signal interference-free, as is demonstrated by an excellent agreement between results obtained relying on the signals for ${ }^{101} \mathrm{Ru}$ and ${ }^{102} \mathrm{Ru}$, respectively. The excellent performance for $\mathrm{Ru}$ is a result of separation of the molten $\mathrm{Pb}$ from the fire assay slag in an inert atmosphere, such that rapidly quenched Pb-buttons are obtained. ${ }^{12}$ Separation of the two phases under air, on the other hand leads to a non-quantitative recovery of $\mathrm{Ru} .{ }^{11}$ For $\mathrm{Pd}$, the results are slightly worse, but can still be considered as satisfactory. Especially for $\mathrm{Pd}$, some heterogeneities in the distribution across the matrix were observed and it is possible that these heterogeneities lead to a somewhat lower accuracy. This hypothesis seems to be backed up by the higher standard deviations observed for Pd. While for the three platiniferous ore reference materials, the results for Ir compare relatively well to the corresponding certified value, for SARM 66, an ore concentrate reference material, a large discrepancy between the experimental results and the corresponding certified value is established. This difference however has to be attributed to a non-quantitative collection of $\mathrm{Ir}$ in the $\mathrm{Pb}$ button as the femtosecond LA-ICP-MS results agree well with those obtained using other solid sampling techniques (spark OES and glow discharge MS) reported in an earlier work. ${ }^{12}$ Finally, also for Au, good results were obtained, except-again-for SARM 66. There seems to be evidence that the certified value for $\mathrm{Au}$ in this reference material is questionable and therefore, the corresponding results were not considered in the calculation, leading to the results summarized in Table 5. From this table, it is also clear that the uncertainty ranges for the experimental results and the corresponding certified values show overlap in all cases for Rh, $\mathrm{Pd}$ and $\mathrm{Pt}$ and in all but one case for $\mathrm{Ru}$. For $\mathrm{Au}$ there is overlap for 4 out of 6 results.

The same set of samples were previously analyzed using a nanosecond LA system-GeoLas ArF* excimer LA-system providing a laser beam with a wavelength of $193 \mathrm{~nm}$ - coupled to a similar type of quadrupole-based ICP-mass spectrometer. By comparing the corresponding results reported in ${ }^{12}$ with those in Table 4, the first conclusion is that the femtosecond LA-ICPMS set-up shows a higher detection power: levels of $\mathrm{Au}$ in SARMs 64 and 65 and of Ir in SARMs $7 \mathrm{~b}$ and 64 that were found to be below the LOD offered by the nanosecond LA-ICPMS set-up could now be determined quantitatively. Of course, this observation is also mirrored in the limits of detection as attainable with both set-ups (Table 3). The superiority of the femtosecond LA system for this application is revealed in several ways, as also the agreement of the experimental results with the corresponding reference values is better: a larger fraction of the experimental results agree with the certified value within 5, 10 and 20\%, respectively, and for a larger fraction of the results, the uncertainty range overlaps with that of the corresponding certified value, while the average difference between the experimental results and the corresponding certified values is smaller for all of the target elements and shows in most cases also a smaller spread. 


\section{Sample throughput considerations}

Self-evidently, the sample throughput benefits from using a large ablation cell housing $10 \mathrm{~Pb}$ buttons, as in-between analysis of two such buttons, obviously the cell does not have to be opened and conditioned again. But other than that, the approach as described in this paper-single hole drilling analysis at 5 different locations for every blank, sample or standard button, daily analysis of the entire set of standards for daily recalculation of the calibration curve-provides high precision and accuracy, but does evidently not provide the highest sample throughput. The sample throughput can be further enhanced by limiting the number of sampling locations to three per button, or, more drastically, by reduction of the frequency with which the calibration curve is updated. We have compared calibration curves for $\mathrm{Rh}, \mathrm{Pd}$ and $\mathrm{Pt}$ determined on several days and could demonstrate that when using the calibration curve established on day 1 for quantification purposes on days 2 and 3, the analysis results differed by less than $10 \%$ with respect to those obtained using a "fresh" curve on all occasions, at least when using the ${ }^{204} \mathrm{~Pb}^{+}$signal as an internal reference. When not using an internal reference, the maximum bias was seen to increase to $\sim 15 \%$.

\section{Conclusions}

The combination of a $795 \mathrm{~nm}$ femtosecond LA-system and a quadrupole-based ICP-MS instrument equipped with a collision/reaction cell was demonstrated to offer an excellent performance for a demanding real-life application - the determination of the levels of the PGMs Rh, Pd, Ru, Ir and Pt and of $\mathrm{Au}$ in $>99 \% \mathrm{~Pb}$ buttons obtained via fire assay of platiniferous ores. The use of matrix-matched standards permitted accurate results to be obtained, despite the severe signal suppression observed upon introduction of this heavy matrix into the ICP. Comparison of the figures of merits and analytical results for ore reference materials obtained in this work with those obtained using a $193 \mathrm{~nm} \mathrm{ArF*}$ excimer-based nanosecond LA-system demonstrated the superiority of the femtosecond system, not only in terms of detection capabilities (3- to 10-fold improvement), but also in terms of accuracy. Accuracy for the more demanding analytes $\mathrm{Rh}$ and $\mathrm{Ru}$, was assured by using chemical resolution providing interference-free conditions and separation of the molten $\mathrm{Pb}$ from the fire assay slag in an inert atmosphere, respectively. In the present research project, the analysis time per sample is approximately $10-15 \mathrm{~min}$ and it has been demonstrated that the sample throughput can be further increased to several tens of buttons per day if not the highest level of accuracy and precision is strived after, but experimental data accurate within $\pm 10 \%$ are acceptable.

\section{Acknowledgements}

FV and MR thank the ETH-Zürich for funding their research stay. MR acknowledges the Government of Aragón and the Spanish Ministry of Science and Innovation (Project CTQ200908606). Markus Wälle and Reto Glaus are thanked for their practical help.

\section{References}

1 www.platinum.matthey.com/applications (25.04.2010).

2 Catalytic Air Pollution Control: Commercial Technology, R. M. Heck, R. J. Farrauto, S. T. Gulati, 3rd edition, John Wiley \& Sons, 2009, ISBN 0470275030.

3 Fuel Cell Fundamentals, R. O'Hayre, W. Colella, Suk-Won Cha, F. B. Prinz, John Wiley \& Sons, 2006.

4 E. D. Kinloch, Econ. Geol., 1982, 77, 1328.

$5 \mathrm{http} / / /$ www.platinum.matthey.com/pgm-prices (25.04.2010).

6 www.preciousmetals.umicore.com/raw_materials_recycling (25.04.2010).

7 J. Haffty, L. B. Riley and W. D. Goss, US Geol. Surv. Bull., 1977, 6(No 1445), 8221.

8 Determination of the Precious Metals: Selected Instrumental Methods, ed. J. C. Van Loon and R. R. Barefoot, John Wiley and Sons, Chichester, 1991, ISBN 0471927457.

9 Assay and Analytical Practice in the South African Mining Industry, W. C. Lenahan and R. de L. Murray-Smith, The South African Institute of Mining and Metallurgy, Johannesburg, South Africa, 2001, ISBN 0620092246.

10 M. Resano, E. García-Ruiz, M. A. Belarra, F. Vanhaecke and K. S. McIntosh, Trends Anal. Chem., 2007, 26, 385.

11 F. Vanhaecke, M. Resano, E. Garcia-Ruiz, L. Balcaen, K. R. Koch and K. McIntosh, J. Anal. At. Spectrom., 2004, 19, 632.

12 M. Resano, E. Garcia-Ruiz, K. S. McIntosh, J. Hinrichs, I. Deconinck and F. Vanhaecke, J. Anal. At. Spectrom., 2006, 21, 899.

13 R. E. Russo, X. L. Mao, J. J. Gonzalez and S. S. Mao, J. Anal. At. Spectrom., 2002, 17, 1072.

14 B. Fernandez, F. Claverie, C. Pecheyran and O. F. X. Donard, Trends Anal. Chem., 2007, 26, 951.

15 J. Koch and D. Günther, Anal. Bioanal. Chem., 2007, 387, 149.

16 T. Hirata and Y. Kon, Anal. Sci., 2008, 24, 345.

17 J. Pisonero and D. Günther, Mass Spectrom. Rev., 2008, 27, 609.

18 M. D. Shirk and P. A. Molian, J. Laser Applic., 1998, 10, 18.

19 R. Hergenroder, O. Samek and V. Hommes, Mass Spectrom. Rev, 2006, 25, 551 .

20 R. E. Russo, X. L. Mao, J. J. Gonzalez and S. S. Mao, J. Anal. At. Spectrom., 2002, 9, 1072.

21 C. Liu, X. L. Mao, S. S. Mao, X. Zeng, R. Greif and R. E. Russo, Anal. Chem., 2004, 76, 379.

22 J. Gonzalez, S. H. Dundas, C. J. Liu, X. Mao and R. E. Russo, J. Anal. At. Spectrom., 2006, 21, 778.

23 J. J. Gonzalez, C. Liu, S. B. Wen, X. Mao and R. E. Russo, Talanta, $2007,73,567$.

24 T. Hirata and Y. Kon, Anal. Sci., 2008, 24, 345.

25 F. Poitrasson, X. Mao, S. S. Mao, R. Freydier and R. E. Russo, Anal. Chem., 2003, 75, 6184

26 J. J. Gonzalez, D. Oropeza, X. L. Mao and R. E. Russo, J. Anal. At. Spectrom., 2008, 23, 229.

27 M. Wälle, J. Koch and D. Gunther, J. Anal. At. Spectrom., 2008, 23, 1285.

28 H. Traub, M. Wälle, J. Koch, U. Panne, R. Matschat, H. Kipphardt and D. Günther, Anal. Bioanal. Chem., 2009, 395, 1471.

29 K. Ikehata, K. Notsu and T. Hirata, J. Anal. At. Spectrom., 2008, 23, 1003.

30 V. Mozna, J. Pisonero, M. Hola, V. Kanicky and D. Günther, J. Anal. At. Spectrom., 2006, 21, 1194.

31 X. Chen and R. S. Houk, J. Anal. At. Spectrom., 1995, 10, 837.

32 F. Vanhaecke, G. Galbács, S. Boonen, L. Moens and R. Dams, J. Anal. At. Spectrom., 1995, 10, 1047.

33 Handbook of Chemistry and Physics 63rd ed., R. C. Weast, CRC Press Inc., 1982, ISBN 0849304636.

34 D. K. Bohme, www.chem.yorku.ca/profs/bohme/research/molecule/ NH3.html (25.04.2010).

35 S. M. Eggins, L. P. J. Kinsley and J. M. G. Shelley, Appl. Surf. Sci., 1998, 127-129, 278

36 I. Horn and D. Günther, Appl. Surf. Sci., 2003, 207, 144.

37 F. Vanhaecke, R. Dams and C. Vandecasteele, J. Anal. At. Spectrom., 1993, 8, 433.

38 I. Kroslakova and D. Günther, J. Anal. At. Spectrom., 2007, 22, 51.

39 C. O'Connor, B. L. Sharp and P. Evans, J. Anal. At. Spectrom., 2006, 21, 556.

$40 \mathrm{~K}$. S. McIntosh, The systems engineering of automated fire assay laboratories for the analysis of the precious metals, $\mathrm{PhD}$ dissertation, University of Stellenbosch, 2004.

41 G. L. Long and J. D. Winefordner, Anal. Chem., 1983, 55, 712A. 